ease to lave heen the same which appears in ordinary seasons. We have to notice also, that the appearance of the blood when in win is not alluded to as a good criterion of the propriety and safety of its abstraction. In short the treatment would lead us to susfiet that the author considers fever and intummation as identical, though, from some passares in the work, be denies this opinion.

Although we have thought it necessary to criticise the indiseriminate adoption of bluaderting in all types of fever, without respect to the circumstances which are accasionally observed in particular epi. demics, and the occurrences in each indirthal case, we nevertheless are strong arrocates for the occasional and prudent antiplilogistic treatment of the disease. Blood. leting forms only one item of this mode of treatment, and though imperiously called for in some epidemics, and necessary to sublue particular symptoms, we are satisfied that its indiseriminate employment can only result from an imperfect experience of llie principles on which the treatment of ferer should be conducted.

Finally, we dissent entirely from the assertion that "the only morbid condition in fever of which we have any knowledge, and over which the medical art possesses any control, is inflammation." Surely Dr. Snith will not deny that we know something of congestion, or that debility sometimes occurs in fever, and be can scarcely contend that over debility we have no control. Again, it does not follow, that because we have no knowledge of the nature of a morbid action, we are therefore not to treat it in the manner which experience, sage though eminic experience, has taught us to be correct. What do we know of the morbid condition of the system in intermittents ? Is inflammation the first condition to be combatted there? Yet this is fever, and for it we suppose Dr. Smith himself, if he were prescribing in the close lanes of Bermond$B C y$ - "cclum, non animum, mutans" wovid desert the lancet and venture on the sulphate of quinine.

liat we have allotted space enough already to this treatise, and we shall pursue its isigrerations no furtber. Before we concinre, however, we have to notice the admission in the eighth ehapter of the author's bylief in contagion, and os we must again. postpone the notice of Dr. Tweedie's Clinical Jllustrations, and M. Dance's Memoir, we shall defer our concluding notice until nother number.

PRACTICAL OBgRRYATIONG ON THE

\section{PATHOLOGY AND TREATMENT}

OP

\section{$D E A F N E S S$.}

\section{No. II.}

\section{By Jonn Fosbroxe, M.D., \&c. \&c.}

IN my first communication on deafness (LAnCET, Jan, 15), I stated, that the exclusive subdifision of the profession under the denomination of pure aurists was absurd and superfluous, as well as useless to tho public, except for picking their pockets; that the histories of cures performed by aurists, whether stationary, sbam, or vagrant aurists, and whether their cures be printed in catchinenny books, in placards on whipping or other posts, chalked on walls, or advertised in venal country newspapers, are, for the most part, nothing but lies to catch ignorant credulity; I wish to impress on the general practitioner, whose avocations are too numerous and various to admit always of his divided attention to a particular subject, the circumstance that there is nothing relative to the ear to which be is not competent, and I recommend him to avail himself of extracts from the remarks of others and myself, for insertion in the provincial press, as far as its system of $a b$ ject servility, venality, and interested suppression of truth, will admit, wherever those remarks may serve to expose the pretenders who come across his path as ear.doctors. I have tried this plan myself with considerable success, in weeding out several descriptions of quacks; for in the despicable state of the medical institutions and medical legislation of this country, the press (and even that is bound hand and foot by an unprincipled libel law more calculated for the defence of scoundrels than the protection of honest men) is the only means we have, of aftording security to the profession and the public, against the successful swarms of these mountebauks. "A caution to the public" in a local journal opon the spot, is to them an excellent lift to general practitioners, a body to whicin I account it honourable to have belonged seventeen years, and from which I am separated, as far as a degree goes, only in compliance with my particular interests. A simplified discussion, with the views I have stated, may be useful, and if, as on former occasiona, some of them can 
assist me with the communication of facts, I impression produced by the extreme ho. shall be glad to receive them.

Symptoms.-Deafness varies from a diminution of hearing, to an almost total extinction of the sense. A noise in the ears, resembling either the roar of the sea, the ebullition of boiling water, or the rustling of the wind among trees, accompanied some. times with noise in the head, exists in almost every case of deafness, to whatever cause the deafness may be owing. The patient, if deaf in both ears, may be deafer on one side than the other. The left ear is almost always the least deaf, though the membrane of the tympanum on that side may have been ruptured. If the deafness of both ears be attended with inflammation of the external porches and disclarge, the discharge is generally most from the right ear.

From obvious causes, the deaf hear better at some times than others, according to the weather, temperature of the air, the state of their bodily and mental health, and various other circumstances. Some hear better in foggy weather, when the air is most dense, moist, and elastic ; on account, perhaps, of the increased force with which the air, in that state, is vibrated by sounds; sudden changes from fine and settled to cold and irregular weather, increase the difficulty of hearing. Analogously, almost all local, and most general diseases, vary from the same impressions. Parts injured or weakened in structure or function being more susceptible, as we all know, than the sound parts of the frame, experience the presentiment of changeable weather with talismanic viracity. Deafness is generally increased during spring and autums, through the rapidand extreme changes of the temperature and moisture of the atmosphere at those seasons, which excite peculiar temporary movements of the circulating and nervous systems in man, as of the first of these systems in plants. Indeed it is often brought on at these seasons from the greater susceptibility of the body, which then exists, to diseases in general, and affections about the throat especially. Our climate, in consequence of its variability, is very productive of deafness. M. Itard, the physician to the Deaf and Dumb Institution of Paris, and a writer of a very able work on the diseases of the ear, informed me, that the deafness of the majority of English who apply to him, is caused by polypi in their nostrils, the frequency of which growths he ascribes to their climate. I became myself bard of hearing in one ear, with scantiness and induration of wax, whilst at Trinity Coll. Dublin. A young Englishman, who weut over to Dublin, with whom $I$ was acquainted, was affected in the same manner. I know of no other cause of these affections, than the midity of the climate of that part of lreland.

The ear is exquisitely sensible of cold. A deaf man going abroad at dewfall, finds his bearing instantly aflected for the worse. The observation generally is, that, as soon as the sole of his shoe is wetted, "he feels the cold fly to his ears." The balance of the circulation being disturbed by a cause applied to one part, the effect may be fett at a more remote and weak part.*

Ilearing is sometimes influenced accorling to the medium and quality of sound. Some hear better amid a loud and uuform noise than in perfect stillness, because, jrobably, the torpid nervous system of the ear, and especially the nervous expansions which supply nervous influence to the membrane of the tympanum and its muscles, require being excited generally to a certain pitch to raise their sensibility to the ordinary stand. ard requisite for receiving vocnl impressions, and distinguishing one class of sounds from another. Others, who cannot comprehend a strange voice at a bawling pitel, can interpret a voice to which they are used habitually and familiarly, just raised above moderate loudness. This circumstanceshows the nicety with which some individuals are able, by constant attention, to recognise particular forms or figures of impression. Others hear only sharp and acute sounds, being much more forcible than long and diffused sounds.

Since morbid impressions of all kinds strike most heavily upon injured parts, almost all incidental deteriorations of health and derangements of other parts of the body produce an aggravation or renewal of this infirmity. Some deaf people find their ears colder and deafer post coitum, an effect produced by other causes of general diminution of vigour. Irregular actions of the skin, heat, dryness, and cold sweats, for instauce, are, in this respect, unpropitious, and oftell conjoined with deafness in hypochondriasis, and certain diseased conditions of the mucous membrane of the alimentary tube, which I have described in my observations on the kidneys. Those two imjortant tissues, the stin and mucous membrane, as forming part of the structure of the ear, and as connected and continuous textures, par. ticipate with each other in disease. Local affections of every kind go wrong, when either of these tissues is out of order.

The state of the mind, that mighty influence upon health, and the cause, when wrong, of the decay and dismantling of the frame, greatly affects the leann of the deaf. The depressing passions așcra-

* For observations on the effect of climate, de, on the ears, and precautionary informatioli, sec M. Rostan on Hygeine. 
rate deafness, and sometimes even call it the head and belind the ears, and especinlly. iuto existence, whilst the exhilarating pas- the improper suppression of local affections stons alleviate it, so long as the patient is of the scalp by local treatment alone, are under their influence. Lady Baghot, who constantly followed by deafuess.

as subject at times to deafness, had alnays a renewal of it after every cause of mental depression. On one occasion, a letter, merely stating the death of a relition, renewed the difficulty of hearing. The Rev. Jeremials Lowe, a patient of mine, states, "I find that any trouble or aldsety increases my difficulty of hearing, and that feelings of a different nature improve it. If I take more wine than usual, or if any-thing exhilarates the spirits or brictes the frame, I am the better for it." These facts indicate the direct operation of the mind in altering the balance of vascular and uervous action.

The period of the day has sometimes an infuence. Some deaf persons bear better in the morning than at night; sometimes the reverse.

Deafuess is generally gradual in its progress. The voice is often very much changed, the deaf not being able to regulate it. One patient writes: "From not hearing my voice, it is to strangers difficult to understand me, which considerably aggrarates my affliction."

Exciting Causes.-These are very difficult to be ascertained. The most universal are, catarrh, exanthematous cases, fever, local affections in neighbouring parts, as ab. scesses and suppressed eruptions of the scalp, syphilis, abuse of mercury, the action of lead, remote affections especially of the bladder and urethra, and external violence; but the chiefest of all is catarrb.

Catarri, scarlatina, small-pox, measles, crnanche tonsillaris, excite dealness, not only by simple extension of inflammation frum the throat to the eustachian tube, but ly striking at the internal ear at once, perhips by determining an irregular flow of blood to the brain and internal ear. I suspect, in many of these cases, a permanently congested state of the veins of the internal ear.* At all events, in uumerous examples, it bas been impossible to trace the continuous and consecutive progress of local disensed action from part to part.

The exposure of the ears to cold, and from negrlect of proper apparel about the head, as is now the fashion among routgoiug women at night and in the open air, tarrachs, with which the patient may be affected three or four years previously, the furmation of abscesses periodically about

- Catarrh is preceded by headach, determination if bloud to the head, unpleasant and restless sensains, and certain feelings of the skin, which are civ ay relueved when the nose begins to run. I roard the catarrh-that is, the increased efflux frum the nostrils, not as the disease itself, but as iur secullary affection, and a salutary process.

"Among the accidental causes of otitis and inflammation, which very rapidly spread to the interior of the ear, and so often in. duce caries of the bones, permanent deatvess, and fatal affections of the brain itself, cold applied suddenly to the ear through the medium of a strean of air, is one of the most common."-M. Lallemand sur l'En. cephalite.

The action being suppressed in one part near the ear, is succeeded by auother in the ear itself. Sometimes abscesses follow in this manner behind the ears, which penetrate in to the meatus externus through a hole in the bone large enough to admit a gold-wire probe; at others, discharges from the meatus externus, with ringing in the ears and hardness of hearing. My case-books are full of facts, which prove the dreadful consequences to the ears and eyes from entrusting cases of the nature thus described to the pernicious treatment of the various descriptions of certain wholly uneducated, or half-educated men, who are permitted to practise in England, especially of that class whom I call druggist-surgeons, and to whom, along with others of the St.-John-Loncr school, I shall shortly call public attentiou, by a full development of their merits.

The permanently debilitating influence of the venereal diseuse upon many, although that disease may be cured in all its local forms, may lead to deafness, by the tendency of reduction of power to increase the susceptibility of the ears to morbid impression; and sometimes, it is said, the disease itself prodnces deafiness by causing venereal action at the anterior orifices of the eustachian tubes. Mercury also, since it debilitates numerous constitutions, when injudicivusly admiuistered, and most of all acts upon the more minute and susceptible organs, is similarly injurious.

Deafness, I have reason to think, may follow the incautious use of water impreymated with lead. One of my patients used water brought through lead pipes, for every domestic purpose, in his diet, and washing his bead. He was subject to colic, very slow bowels, and stitches in different parts of his body, especially the muscles of his chest, under which he found it difficult to breathe.

Affections of the bladder and urethra appear particularly to bring on deafness, or produce a relapse of it. In two cases of stricture of the urethra, attended with extreme irritability of the part affected, and participation of the whole constitution in the local affection, and in a third case of diseased bladder under my care, deafness took place, but gradually disappear- 
ed with the amendment of the original disease. Mr. F. came to me in 1828 for stricture of the urethra, and spontaneous emission every morning, seemingly from the vesicula seminales. 'The emission ceased after the cure of the stricture, and he was immediately seized with singing of the ears and deafness. An babitual bamorrhage from the nose had also ceased. He heard very well when he was swallowing, and $I$ therefore ascribed his deafness to his throat; leeching relieved his head but not his ears. In this case I think the deafness was owing to change of determination consequent on the ceasing of the discharges.

Other causes of deafness are local and mechanical, as in deafness caused by the sudden explosion of cannon, and that by continned noise, as blacksmiths' deafness. 'The former is ascribed to rupture of the membrane of the tympanum by the force of the vibratory impulse, when the ear being taken by surprise the membrane consequently is not regulated and prepared by its muscles to encounter the shock. I conceive that this accident is most likely to bappen, as we know the structure of the ear to be various in that respect, where the meatus is very straight in its course, and the membrane of the rympanum is less oblique than com. monly in its position. "Nonnulli statuunt," says the learned Sennert, "membranam hanc et acutissimo et vehementissimo zono, et bombardarum et campanarum ingenti sonitu, sicut et a frigore vehementi, non dolore solum affici, sed et rumpi posse. Alii tamen nimis saltem tendi a talibus vehementibus objectis membranam hanc existimant, atque ita nimis tensam laxiorem reddi, ut sonum amplius edere non possit." Dr. Parry records two cases of deafness from extreme noise; that of Lord Rodney after the eighty broadsides fired from his ship the Formidable, in 1782; a second from the re: port of a cannon close to the individual at the battle of Copenhagen. The blacksmiths' deafness is a consequence of their employ. ment; it creeps on them gradually, in general at about forty or fifty years of age. At first the patient is insensible of weak impressions of sound; the deafness increases with a ringing and noise in the ears, slight vertigo, and pain in the cranial bones, periodical or otherwise, and often violent. No wax is formed. It has been imputed to a paralytic state of the nerve, occasioned by the uoise of forging, by certain modern writers, and by the old writers, to permanent ovtr-tension of the membrane, which they compare to fixed dilatation of the pupil.

Sudeley Place, Cheltenham, January 17, 1831.

\section{CASE OF HYDROCEPHALUS,}

IN WHICH THE OPERATION OF TAPPING WaS PERFORMED.

Treated by W. MansDen, Esq., of Londun, M.R.C.S.

ON the 16th Dec. last, an infant, aged sir. teen months, was brought to me, which had been afflicted upwards of a year. Her ap. pearance and symptoms were, tumid abdo. men; flesh flabby and spare; skin colour. less, soft, and relaxed; eyes full and bright; pupils greatly dilated, and the retina insen. sible to light. Nausea, with occasional ro. miting, had existed for a considerable period; the alvine evacuations were pale, watery, and frequent ; urine scanty and high-coloured; tongue dry and dark; respiration and pulse both very quick and feeble, and for several months the child was generally in a comatose state. It had short intervals of screeching, with occasional convulsire fits, but neither of these symptoms was violent; had taken the breast and other food treely till within the last three weeks ; and durnng the last two days had rejected every thing, except a little barley-water given in a teaspoon. The extremities were cold; the skin was damp, and, to all appearances, life was fast drawing to a close. I had no doubt respecting the nature of the case, nor any with regard to the impropriety of relying solely on medicinal treatment. I therefore concluded that it was a proper case for the operation of tapping, although by no means a favourable one for recovery, - other visceral disease existing, and the vital power being already too much enfeebled by the long continuance of pressure on the brain.

Having stated my opinion to the chld's parents, they consented to any plan I might think proper to adopt: I therefore at once proceeded to the operation of tapping, assisted by my friend MIr. Greville Jone's. The child being placed on a table in a supiat. position, its head half inclined to the left resting on a pillow, with a common hydrocele trocar, a perforation of the membranes was made at the left coronal suture, midway between the fontanella and the temporal bone (the suture at this part being openl); and having introduced the instrument onle inch and a half into the brain, the stiletto was withdrawn, when about sixteen ounces of transparent colourless fluid were gradually drawn off, after which the canula was withdrawn, and the wound leftopen. $A$ bandage was applied to the chlld's head, but the sutures being generally closed, this was of little or no utility. The operation $F$ is performed within the space of tive minutes, and not a drop of blood was spilled. The child was then placed in the cradle, in a 